\title{
A ESTRUTURA DA PAISAGEM DO MOSAICO FORMADO PELAS UNIDADES DE CONSERVAÇÃO PRESENTES NO LITORAL NORTE DO PARANÁ
}

\author{
Mayssa Mascarenhas Grise ${ }^{1}$, Daniela Biondi ${ }^{2}$, Christel Lingnau ${ }^{2}$, Hideo $_{\text {Araki }}{ }^{3}$ \\ ${ }^{1}$ Bióloga, M.Sc., Curitiba, PR, Brasil - mayssa@onda.com.br \\ ${ }^{2}$ Eng $^{\mathrm{a}}$. Florestal, Dra ${ }^{\mathrm{a}}$, Depto. de Ciências Florestais, UFPR, Curitiba, PR, Brasil - dbiondi@ufpr.br - lingnau@ufpr.br \\ ${ }^{3}$ Cartógrafo, Dr., Depto. de Geomática, UFPR, Curitiba, PR, Brasil - haraki@ufpr.br
}

Recebido para publicação: 08/10/2008 - Aceito para publicação: 09/03/2009

\begin{abstract}
Resumo
O presente trabalho teve como objetivo analisar a estrutura da paisagem, matriz e fragmentos, das unidades de conservação (UCs) que ocorrem sobrepostas à Área de Proteção Ambiental (APA) de Guaraqueçaba, a fim de verificar a funcionalidade do mosaico formado por essas UCs. A partir da classificação supervisionada da imagem digital Landsat-5, realizou-se a classificação da cobertura do solo e foram definidos os atributos de área e perímetro dos polígonos obtidos. Através da análise da estrutura da paisagem, constatou-se que as UCs se conectam pela matriz de vegetação nativa interrompida pela presença de fragmentos. Os fragmentos cobrem 21,40\% da área de estudo, pertencem às classes de vegetação alterada, solo descoberto, áreas urbanizadas, areia e água, sendo que grande parte possui menos de um hectare e têm forma regular. As categorias de manejo dessas áreas condizem com os objetivos citados em seus decretos de criação. As zonas de amortecimento das UCs de proteção integral não estão totalmente inseridas nos limites das APAs Federal e Estadual de Guaraqueçaba. Conclui-se que, quando observadas em conjunto, cada UC contribui para a conservação da paisagem local, formando um mosaico funcional de áreas naturais protegidas segundo os fundamentos da estrutura da paisagem e da legislação do mosaico.

Palavras-chave: Fragmento; matriz; Floresta Atlântica; Guaraqueçaba.
\end{abstract}

\begin{abstract}
The mosaic landscape structure formed by conservation units in north coastal of Paraná. The objective of this study was to analyze the landscape structure, matrix and patches, of the conservation units (CUs) that occur in the same area of Environmental Protection Area (EPA) of Guaraqueçaba to verify the mosaic functionality formed by these CUs. From the supervised classification of digital image Landsat-5 was defined the land cover classes and the area and perimeter attributes of polygons obtained. According to the landscape structure analysis, was observed that the CUs were communicated through native vegetation matrix interrupted by the presence of patches. The patches cover $21,40 \%$ of the studied area, which belong to classes of changed vegetation, exposed soil, urban areas, sad and water; mostly have less than one hectare and have a regular shape. The management categories of these areas match with the goals in each CU decree creating. The buffers zones of integral protection CUs are not fully incorporated within the limits of EPAs Federal and State of Guaraqueçaba. It concludes that, when taken together, each CU contributes to the local landscape conservation, promoting a functional mosaic of natural protected areas, according to the landscape structure and mosaic's laws.
\end{abstract}

Keywords: Patches; matrix; Atlantic Forest; Guaraqueçaba.

\section{INTRODUÇÃO}

A perda e a fragmentação de hábitats é a principal ameaça à diversidade biológica do planeta. A melhor maneira de proteger a biodiversidade em longo prazo é a conservação in situ (PRIMACK; RODRIGUES, 2002), a qual se faz com o estabelecimento de áreas protegidas (BENSUSAN, 2006). Com 
a diminuição e fragmentação de hábitats, as paisagens naturais se transformaram em mosaicos formados por manchas isoladas do hábitat original, conduzindo à perda de espécies (FERNANDEZ, 1997).

No Brasil, o Sistema Nacional de Unidades de Conservação (SNUC) instituiu e normatizou as áreas protegidas denominadas de Unidades de Conservação (UCs) (BRASIL, 2000). Entretanto, apenas o estabelecimento de UCs não garante a preservação de uma área, um ecossistema ou uma espécie (TOSSULINO et al., 2006). Existe a necessidade de melhorar a conservação nas UCs já existentes. Um conjunto de medidas deve ser posto em prática para que uma UC contribua desde sua concepção para a conservação da natureza e para produzir resultados no aumento da expressividade e da estabilidade dessas UCs (CAMPOS; COSTA FILHO, 2006).

Entre as medidas necessárias para que uma UC contribua realmente para a conservação, está a formação de mosaicos de áreas protegidas (DAVEY; PHILLIPS, 1998; BRASIL, 2000; PHILLIPS, 2002; THOMAS; MIDDLETON, 2003; BENNETT; MULONGOY, 2006; DUDLEY; PARISH, 2006). Segundo o SNUC (BRASIL, 2000), um mosaico é uma área formada por um conjunto de UCs de categorias de manejo diferentes ou não, que estejam próximas, justapostas ou sobrepostas, e cuja gestão deve ser feita em conjunto, de forma a compatibilizar a conservação da biodiversidade com o contexto regional.

O Estudo da Paisagem, a ciência que trata das paisagens, constitui uma importante ferramenta, auxiliando no estabelecimento de prioridades de conservação, na definição de novas áreas de proteção e no manejo de áreas protegidas (MILANO, 1990). O termo paisagem possui uma série de definições que diferem entre os autores, seja por sua formação e ponto de vista, seja pelo enfoque que lhe é dado (BIONDI, 2005). Forman; Godron (1986) definem paisagem como uma área de terra heterogênea e composta de agrupamentos de ecossistemas interligados que se repetem de forma similar em todo lugar.

Os três elementos espaciais que estruturam uma paisagem são a matriz, os fragmentos e os corredores. Eles formam mosaicos que são responsáveis pela diversidade de paisagens, apresentando modelos espaciais com diferentes componentes (FORMAN, 1995; MARENZI, 2000), sejam componentes naturais, como o relevo, a litologia, o clima, o solo, a água, a vegetação e a fauna, sejam componentes artificiais, advindos da influência humana (BIONDI; LEAL, 2002). Com base nos padrões espaciais da paisagem, a ecologia da paisagem tem discutido as melhores formas de planejamento de áreas de conservação para a proteção da diversidade biológica, a fim de se compreender a influência da composição da estrutura das paisagens nos processos ecológicos (METZGER, 2003).

Assim, os mosaicos compostos por diferentes UCs formam paisagens cuja análise dos conceitos relacionados à sua estrutura traduz a dinâmica de cobertura e ocupação do solo, fundamentais para a sua conservação. Os elementos estruturais das paisagens podem ser avaliados e estudados de forma a contribuir para a manutenção de áreas protegidas, bem como na elaboração de planos de manejo e estratégias de conservação, não focando UCs de forma isolada, mas considerando mosaicos de unidades de conservação.

A expansão do Sistema de Unidades de Conservação no Brasil é uma preocupação, uma vez que se estima que as áreas naturais se esgotem nas próximas duas décadas, tornando imprescindível a identificação de estratégias, em larga escala, que auxiliem na manutenção do sistema de áreas remanescentes em um cenário de pressão crescente. Como estratégias apontadas para o equacionamento das alterações pelas quais passam comunidades animais e vegetais, estão os conhecimentos advindos dos estudos de ecologia e manejo de paisagens (FONSECA et al., 1997).

Devido à generalizada eliminação de hábitats, as UCs tendem a se tornar os últimos refúgios para muitas espécies e as únicas amostras dos ecossistemas em sua composição original. Seu valor como amostragem da biodiversidade do planeta é imensurável e crescerá na medida em que os ambientes naturais forem desaparecendo. No entanto, tais áreas geograficamente limitadas tendem a uma inevitável simplificação biológica ao longo do tempo, cuja minimização só poderá ser alcançada com seu manejo eficiente. Essas áreas somente serão viáveis com o conhecimento das espécies protegidas, não apenas para permitir o acompanhamento da dinâmica populacional, como também para indicar lacunas e sugerir medidas corretivas (MIKICH; BÉRNILS, 2004).

Não basta apenas a proteção de áreas naturais, mas também seu delineamento e conectividade com outras áreas de conservação. Para assegurar que sejam mantidas as espécies e sua variabilidade genética, é necessário o manejo adequado, que se faz a partir da aplicação do estudo da paisagem e da biologia populacional (FERNANDEZ, 1997; MILLER, 1997; MILANO, 2000; PÁDUA, 2002). A 
questão ambiental deve ser analisada no contexto global da paisagem, e não a partir da propriedade (CARPANEZZI et al., 2006).

Para o estudo da paisagem, tem se expandido o uso de técnicas do sensoriamento remoto e do sistema de informações geográficas, devido a sua adaptabilidade e acessibilidade (FORMAN, 1995), oferecendo meios para uma análise quantitativa da estrutura da paisagem (PRIMACK; RODRIGUES, 2002).

O estado do Paraná detém a maior parcela contínua de Floresta Attântica do País, bioma de maior biodiversidade do mundo e também o mais ameaçado. O litoral do estado é formado por várias UCs das mais diversas categorias de manejo. Entre essas está a Área de Proteção Ambiental (APA) Federal de Guaraqueçaba, uma das últimas áreas representativas da Floresta Atlântica no país. Nos limites de área desta APA estão inseridas outras UCs de diferentes categorias de manejo.

A região, por suas características de alto valor ecológico, foi foco de atenção das políticas públicas de meio ambiente, possuindo uma série de diplomas legais (SPVS, 1992; IPARDES, 1997; IPARDES, 2001). Tamanha riqueza biológica fez do litoral norte paranaense a primeira área no Brasil instituída pela UNESCO, em 1991, como Reserva da Biosfera da Mata Atlântica. Novas áreas foram agregadas posteriormente, sendo hoje a maior e uma das mais importantes unidades da Rede Mundial da UNESCO, que inclui 440 Reservas da Biosfera em 97 países (RBMA, 2006). Entretanto esses diplomas legais foram criados ao longo de anos e de forma isolada, deixando a dúvida de sua real contribuição para a preservação de uma área de importância imensurável, uma vez que reflete a história e a beleza do Brasil.

O objetivo deste trabalho foi verificar, a partir da análise dos elementos estruturais da paisagem, matriz e fragmentos, a funcionalidade espacial do mosaico de UCs do litoral norte do estado do Paraná.

\section{MATERIAL E MÉTODOS}

\section{Seleção da área de estudo no litoral norte do Paraná}

No litoral norte do estado do Paraná localiza-se a maior parcela remanescente contínua de Floresta Atlântica do Brasil, floresta tropical entre as mais ameaçadas do planeta (SPVS, 1992; IAP, 1999; IPARDES, 2001). Essa área engloba a totalidade do município de Guaraqueçaba e parte dos municípios de Campina Grande do Sul, Antonina e Paranaguá (Figura 1). Várias UCs foram criadas ao longo dos anos para proteger a região, formando um mosaico de áreas protegidas.

A área de estudo foi definida como sendo a de abrangência da APA Federal de Guaraqueçaba e das UCs sobrepostas à área dessa APA. Tal definição deveu-se ao fato de a área ser um mosaico de áreas protegidas, por possuir UCs de diferentes categorias de manejo, como a Estação Ecológica (EE) de Guaraqueçaba, o Parque Nacional (PN) do Superagui, a APA Estadual de Guaraqueçaba e as Reservas Particulares do Patrimônio Natural (RPPN) de Águas Belas e Salto Morato, todas sobrepostas à APA Federal de Guaraqueçaba.

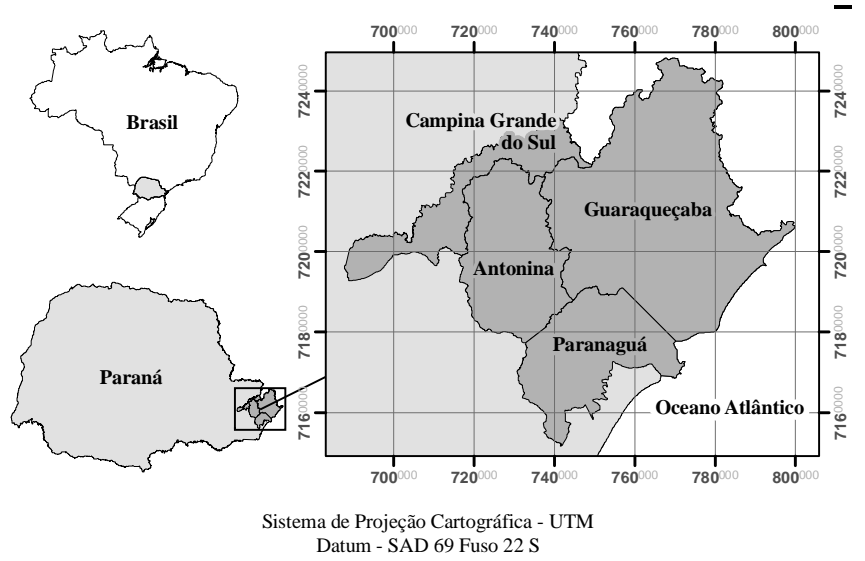

Figura 1. Localização da área de estudo.

Figure 1. Study area location. 


\section{Base de dados}

A análise da estrutura da paisagem foi realizada a partir de duas cenas do satélite Landsat 5 TM - cenas 220/077 e 220/078 (órbita/ponto), de 02 de setembro de 2002, com resolução espacial de 30 metros. Considera-se que o erro gráfico aceito em cartografia é de $0,2 \mathrm{~mm}$ e em sensoriamento remoto é de 1/2 pixel. Para a resolução espacial de $30 \mathrm{~m}$ do satélite Landsat $5 \mathrm{TM}$, a escala de trabalho foi de aproximadamente 1:75.000.

Foram utilizadas cartas do IBGE do estado do Paraná 1:50.000 e 1:100.000, cedidas também pela Secretaria de Estado do Meio Ambiente (SEMA), Divisão de Geoprocessamento e Sensoriamento Remoto, escanerizadas e georreferenciadas.

Os softwares utilizados em cada etapa de trabalho foram o ENVI 3.5 e o MultiSpec Win32 para o processamento da imagem, ArcGis 9.1 para o processamento da imagem e cálculos de perímetro e área e Microsoft Office Excel 2003 para os cálculos estatísticos.

\section{Procedimentos metodológicos}

Processamento da imagem digital

Primeiramente foi realizado um mosaico com as duas cenas do satélite Landsat $5 \mathrm{TM}$ - cenas 220/077 e 220/078 (órbita/ponto). A área de estudo foi então delimitada preliminarmente e recortada no software ENVI 3.5. A imagem passou pelo processo de correção da geometria a partir das cartas do IBGE do Paraná 1:50.000 e 1:100.000.

Após a correção geométrica, a imagem passou pela classificação digital supervisionada pelo método da máxima verossimilhança no software MultiSpec. Utilizaram-se amostras de treinamento para a definição das seguintes classes de cobertura do solo: vegetação nativa, vegetação nativa mangue, vegetação nativa sombreada, vegetação alterada, vegetação alterada cultura, áreas urbanizadas, solo descoberto e água.

A areia também representou uma classe de cobertura do solo, entretanto sua definição a partir das amostras de treinamento não foi possível, devido à resposta espectral da areia e de determinadas áreas urbanizadas se confundirem. As áreas com areia foram então definidas a partir da elaboração de uma máscara, utilizando-se os Índices de Artificialidade DoA e NandA:

$$
\begin{aligned}
& \operatorname{DoA}=\frac{G-R}{G+R} \\
& \text { Nand } A=G-(R+B)
\end{aligned}
$$

Em que: $\mathrm{R}=$ intensidades dos pixels na banda vermelho;

$\mathrm{G}=$ intensidades dos pixels na banda verde;

$\mathrm{B}=$ intensidades dos pixels na banda azul.

Para se estimar a acurácia das amostras de treinamento, foi realizada a avaliação através da matriz de confusão. Na matriz de confusão foi observada a condição de minimização dos erros de classificação das amostras de cada classe, de forma que a matriz não apresentasse valores fora da diagonal, ou seja, $100 \%$ de acerto de classificação para as amostras de cada classe.

Após o processamento da classificação digital, a presença de pixels isolados foi suprimida utilizando-se um filtro de moda $3 \times 3$.

\section{Edição da imagem}

Após a filtragem, a imagem digital classificada no formato raster foi transformada em uma imagem vetorial (formato shape file), formando polígonos. A edição da imagem temática foi realizada atribuindo-se aos polígonos os atributos de classes de cobertura do solo - incluindo a máscara com a classe areia, e os atributos de área e perímetro.

A imagem classificada foi editada, tendo sido definidas as seguintes classes de cobertura do solo: a) água: áreas com presença de água; b) vegetação nativa: áreas de vegetação natural com formação densa; foram incluídas as áreas de vegetação nativa sombreada e áreas de formação pioneira de influência flúvio-marinha; c) vegetação alterada: áreas de vegetação com alterações de densidade de cobertura vegetal, também as áreas de cultura; d) solo descoberto: áreas com o solo sem cobertura; e) áreas urbanizadas: áreas com presença de construções e asfalto; f) areia: áreas com presença de areia. 
As Unidades de Conservação tiveram seu contorno (limites) digitalizado no software ArcGis 9.1. O delineamento das Unidades foi realizado a partir da descrição dos limites geográficos contidos nos decretos de criação das Unidades, com o apoio de cartas 1:50.000 e da imagem digital Landsat. Apenas para a delimitação da Estação Ecológica de Guaraqueçaba foi utilizado como base, além das cartas e de seu decreto de criação, um arquivo vetorial cedido pela SEMA, devido à complexidade de limites dessa $\mathrm{UC}$, que é formada por 14 (catorze) áreas distintas de mangue.

Obtidos os contornos das UCs e definida a imagem vetorial das classes de cobertura do solo, foram conferidos à imagem os atributos de área de cobertura e classes de perímetro.

Classes de área de cobertura

As classes de área de cobertura foram definidas após a tabulação dos valores referentes à área dos polígonos. As classes variaram de fragmentos menores que 1,0 ha a fragmentos maiores que 1.000 ha, sempre com variações decimais, como segue: a) menor que 1,0 ha; b) 1,0 a 10 ha; c) 10 a 100 ha; d) maior que 100 ha.

Classes de perímetro

As classes de perímetro basearam-se no índice de forma dos fragmentos, calculado com base em Forman; Godron (1986), segundo a fórmula:

$$
\mathrm{IF}=\frac{\mathrm{P}}{2 \sqrt{\pi} \mathrm{A}}
$$

Em que: IF = índice de forma do fragmento;

$\mathrm{P}=$ perímetro;

$\mathrm{A}=$ área.

O menor valor possível para o índice de forma, representado pela letra "D", é 1,0 (um), que representa a forma mais circular que um polígono pode apresentar. Deve-se considerar que, quanto mais distante do valor 1,0 (um), mais irregular será a forma do fragmento.

As classes de perímetro foram definidas após os cálculos e tabulação do índice de forma de todos os polígonos. As classes variaram de fragmentos com menos de 1,13 de índice de forma a fragmentos com mais de 2,5, sempre com variações equivalentes: a) menor que 1,5; b) 1,5 a 2,0; c) 2,0 a 2,5; d) maior que 2,5.

Também foram calculadas a média, a moda e a mediana do índice de forma dos fragmentos. Para a análise desses dados, foi elaborada uma escala segundo o grau de pressão que os fragmentos exercem sobre a matriz: a) grau de pressão 1 : índice de forma menor que 1,$5 ;$ b) grau de pressão 2 : índice de forma entre 1,5 e 2,0; c) grau de pressão 3: índice de forma maior que 2,0.

Essa escala foi baseada em Forman; Godron (1986) e Forman (1995). Os autores expõem a fórmula de cálculo do índice de forma e apresentam a interpretação dos valores obtidos. Valores próximos a 1,0 representam formas mais circulares (1,0 representa a forma de um círculo perfeito), enquanto valores como $3 \mathrm{e}$ 4 representam formas bastante irregulares. Considera-se que quanto mais irregular a forma de um fragmento maior será sua área afetada pela borda e, consequentemente, menor será sua área de interior.

\section{Análise da estrutura da paisagem}

Após a definição dos atributos e suas classes, eles foram analisados e relacionados uns com os outros, como a quantidade de polígonos referente a cada classe de cobertura do solo em relação às classes de área de cobertura e de perímetro.

Definição da matriz e dos fragmentos

A matriz foi definida segundo o método da área relativa proposto por Forman; Godron (1986). A classe de cobertura do solo de maior área foi definida como a matriz da paisagem. Após a definição da matriz, todos os demais polígonos foram definidos como fragmentos. Os corredores não foram abordados neste trabalho devido ao tempo limitado para a sua realização.

A porosidade da matriz, segundo Forman; Godron (1986), é a quantidade de fragmentos que perfuram ou interrompem a matriz. Quanto maior o número de fragmentos confinados na matriz, mais porosa ela será. Assim, baseado em Forman; Godron (1986), adaptado à escala deste trabalho, a porosidade da matriz das UCs foi definida a partir da estimativa da quantidade de fragmentos a cada 100 ha. Foram determinadas as seguintes classes de porosidade: a) porosidade baixa: menos de 2 fragmentos 
por $100 \mathrm{ha}$; b) porosidade média: entre 2 e 4 fragmentos por $100 \mathrm{ha}$; c) porosidade alta: mais de 4 fragmentos por 100 ha.

Essas classes de porosidade foram elaboradas a partir dos resultados obtidos para este trabalho. Estimando-se a quantidade de fragmentos em cada UC, chegou-se a valores entre 1 (um) e 6 (seis), e então a escala foi definida. Dessa maneira, foi possível a comparação do grau de porosidade entre as UCs.

Análise do mosaico de Unidades de Conservação

O mosaico formado pelas 6 (seis) UCs foi analisado segundo 3 aspectos: a) estrutura da paisagem das UCs - a partir dos atributos de classes de cobertura do solo, área e perímetro, bem como da definição da matriz e dos fragmentos das UCs; b) legislação das UCs e de Mosaico - com base no SNUC (BRASIL, 2000), verificou-se se os objetivos e categorias de manejo das UCs são coerentes aos decretos de criação e principalmente aos elementos estruturais da paisagem (matriz e fragmentos); c) zona de amortecimento - a EE e o PN devem possuir uma zona de amortecimento, entretanto não possuem seu limite definido em decreto, de modo que foi adotada a definição de $10 \mathrm{~km}$ estabelecida pela Resolução do Conselho Nacional do Meio Ambiente (CONAMA) no 13/90, de 6 de dezembro de 1990, em seu Art. $2^{\circ}$. Foram criados buffers de $10 \mathrm{~km}$ a partir do limite da EE e do PN e verificado o uso do solo nessas áreas (BRASIL, 1990).

Comparando-se a matriz e os fragmentos, bem como seus atributos e suas inter-relações, os aspectos legais e as zonas de amortecimento da área total das UCs e quando estas foram analisadas individualmente, foi possível a mensuração da funcionalidade do mosaico de UCs do litoral norte do estado do Paraná.

\section{RESULTADOS E DISCUSSÃO}

Devido à sobreposição da APA Federal de Guaraqueçaba (criada em 1985) com outra UC (a APA Estadual de Guaraqueçaba, criada em 1992), cujos limites extrapolaram sua área de abrangência, foi então delimitada como área de estudo a área ocupada pela junção do contorno dessas UCs, totalizando 310.419,43 ha.

A utilização das imagens digitais Landsat 5 TM com resolução espacial de $30 \mathrm{~m}$ para a realização da análise da estrutura da paisagem da APA de Guaraqueçaba se mostrou satisfatória. Numa área de 310.419,43 ha foram definidos 12.271 polígonos representando as classes de cobertura do solo. A extensão da área e sua fragmentação, a disponibilidade da imagem Landsat e a proposta de realizar uma análise macroespacial da estrutura da paisagem foram fatores que justificaram a utilização dessas imagens e sua resolução. A realização da correção geométrica ocorreu com as cenas 220/078 e 220/079 em mosaico e com o recorte preliminar da delimitação da área de estudo. Para tal, foram definidos 37 pontos de controle na imagem. O RMS total foi de 0,73 pixel, equivalente a 21,90 m. O RMS total foi aceitável, uma vez que é inferior a $30 \mathrm{~m}$ ou 1 pixel.

As amostras de treinamento foram 97 e passaram pela análise da acurácia através da matriz de confusão. O acerto de pixels das diferentes classes das amostras de treinamento foi $100 \%$, ou seja, não houve confusão entre as amostras de treinamento estabelecidas.

\section{Análise da estrutura da paisagem das UCs}

Estação Ecológica de Guaraqueçaba

A EE de Guaraqueçaba totalizou 4.964,20 ha formados, em grande parte, por áreas de vegetação nativa, a qual representou a matriz da paisagem dessa UC, com 97,99\% da cobertura do solo. Esse fato é condizente com o proposto para uma UC de proteção integral, uma Estação Ecológica que tem como objetivo a conservação da natureza e realização da pesquisa científica, obedecendo a uma série de restrições de uso. Grande parte da área é formada por mangue, vegetação também contemplada como área de preservação permanente segundo o Art. $2^{\circ}$ da Lei 4.771, que instituiu o novo Código Florestal Brasileiro (BRASIL, 1965). Quanto à porosidade, foram encontrados 267 fragmentos na matriz. Estimando-se a densidade dos fragmentos, não levando em conta suas localizações, tamanho e forma, são 5,38 fragmentos a cada 100 ha. A porosidade é considerada alta. Entretanto, trata-se de uma UC com área descontínua, definida em decreto pela presença de 14 porções de mangue (BRASIL, 1982). E, ainda, 84 fragmentos são de água, áreas naturais marinhas, fragmentos estes de origem natural, que têm um impacto 
menor sobre a matriz de vegetação nativa. Os fragmentos representam 2,01\% da EE e são, na maioria $(45,69 \%)$, áreas de solo descoberto. A maioria dos fragmentos possui menos de 1,0 ha $(91,76 \%)$, e 8,24\% possuem entre 1,0 e 10 ha. Os fragmentos maiores que 1,0 ha são poucos, uma vez que a EE é formada por pequenas áreas esparsas de mangue. Os fragmentos importantes dessa paisagem são os de áreas urbanizadas e os de vegetação alterada, os quais irão interferir diretamente na matriz de vegetação nativa. São 55 fragmentos de vegetação alterada e 6 de área urbanizada, todos com menos de 1,0 ha.

Quanto às classes de perímetro, a maioria $(44,57 \%)$ possui índice de forma menor que 1,5 , de grau de pressão 1 . Os fragmentos que possuem índices considerados de grau de pressão 3, isto é, fragmentos que apresentam maiores irregularidades em sua forma, são na maioria de água. Esses fragmentos são de origem natural e formam faixas de água do mar no entorno das áreas de mangue.

A classe de água apresentou a maior média $(3,73)$ e também a maior mediana $(2,37)$. A maior irregularidade na forma dos polígonos de água deve-se ao fato desses polígonos se apresentarem alongados, contornando a EE. O índice de forma dos fragmentos de área urbanizada apresentam valores elevados para média $(2,33)$, mediana $(2,28)$ e moda $(2,28)$, valores estes que representam o grau de pressão 3 , que causa maior impacto na matriz.

O estudo da paisagem da EE de Guaraqueçaba torna-se interessante por se tratar de uma área descontínua de terra a ser analisada. Sendo assim, a matriz dessa paisagem é interrompida, não somente pela presença de fragmentos, mas também pelas características de delimitação de sua área, o que vai contra a Forman; Godron (1986), Forman (1995) e aos pressupostos da conservação em áreas protegidas (DAVEY; PHILLIPS, 1998; PRIMACK; RODRIGUES, 2002). Tais autores colocam que uma área protegida deve ter uma porção única de terra e que essa área deve se comunicar com outras áreas protegidas. A área dessa UC deveria ser uma porção de terra única, homogênea e que abrangesse as áreas de mangue de interesse e ainda as áreas marinhas, as quais fazem parte e interferem diretamente no mangue.

Outro aspecto que mostra controvérsia é relativo à área de cobertura da $\mathrm{EE}$, a qual apresenta diferentes dimensões, segundo a fonte de referência. O Instituto Brasileiro do Meio Ambiente e dos Recursos Naturais Renováveis (IBAMA, 2008) apresenta a área dessa UC com 4.831,00 ha, enquanto o decreto de criação da unidade (BRASIL, 1982) descreve 14 áreas, que totalizam 13.638,90 ha. Esta pesquisa baseou-se nas informações do arquivo, cedido pela SEMA, com a delimitação de área que correspondeu a 4.964,20 ha, valor condizente ao que apresenta o IBAMA.

Área de Proteção Ambiental Federal de Guaraqueçaba

A APA Federal totalizou $281.284,55$ ha da APA, 77,94\% coberto por vegetação nativa, a qual representou a matriz da paisagem dessa UC. A porosidade dessa matriz é formada por 9.213 (nove mil, duzentos e treze) fragmentos dispersos na área da APA. Estimando-se a densidade de fragmentos, sem considerar a sua localização, seu tamanho e forma, são cerca de 3,28 fragmentos a cada 100 ha. Nesse caso, a porosidade é considerada média.

Tais dados corroboram o descrito no SNUC, no qual uma APA é caracterizada por ser uma área geralmente extensa de terra, com certo grau de ocupação humana, com objetivos básicos de proteger a diversidade biológica, disciplinar o processo de ocupação e assegurar a sustentabilidade do uso dos recursos naturais (BRASIL, 2000).

A APA é formada, em grande parte, por fragmentos com menos de 1,0 ha, os quais representam $73,82 \%$, sendo a maioria deles fragmentos de vegetação alterada e solo descoberto. A grande quantidade de pequenos fragmentos de vegetação alterada e solo descoberto pulverizados na matriz torna-a mais porosa e aumenta a área de vegetação nativa que sofre pressão das atividades humanas, o que é desvantajoso para a conservação dessa UC.

Os fragmentos de área urbanizada correspondem a 14,18\% e possuem, em sua maioria, menos que 10 ha. São os que maior impacto exercem sobre a matriz de vegetação natural, uma vez que fragmentos de área urbanizada geralmente são classificados como introduzidos, ou seja, têm em sua origem (ou mecanismo de causa) as atividades humanas, as quais têm um efeito contínuo e de domínio sobre o fragmento. Tais fragmentos são, portanto, considerados estáveis e persistentes (FORMAN; GODRON, 1986).

A porosidade é considerada média (3,28 fragmentos a cada 100 ha), sendo que a grande quantidade de pequenos fragmentos dispersos por toda a APA é preocupante. Os valores encontrados seriam ainda maiores se fosse realizado um estudo com imagem de maior resolução espacial. Estudo realizado por Amato et al. (2000) sobre a evolução da cobertura do solo na APA de Guaraqueçaba nos 
anos de 1989, 1994, 1997 e 1999 revelou uma condição de relativa estabilidade da área total desflorestada, não tendo sido verificadas modificações substanciais nas áreas totais de floresta pouco alterada e muito alterada. Entretanto, o autor ressalta que pequenos desmatamentos acabam por ocorrer de forma pulverizada por toda a APA.

Assim como predominam os fragmentos com menos de 1,0 ha $(73,82 \%)$, também ocorre o predomínio de fragmentos com menos de 1,5 de índice de forma $(74,93 \%)$ de grau de pressão 1 , ou seja, valor que mais se aproxima do índice que representa a melhor relação perímetro/área. Quanto mais regular a forma do fragmento, menor será a área da matriz afetada pela borda do fragmento. Tal relação é positiva, uma vez que a matriz da APA é a vegetação nativa, e quanto menos esta sofrer pressão dos fragmentos antropizados, melhor será a sua conservação.

A maior média do índice de forma dos fragmentos foi para água $(1,65)$ e areia $(1,58)$, fragmentos alongados que formam faixas de água e areia que contornam as ilhas da APA. A mediana variou entre 1,20 e 1,39, sendo o maior valor encontrado para água. A moda, para as classes de cobertura do solo, foi de 1,13 (exceto para área urbanizada - 1,20), que é o índice de forma mais regular encontrado neste estudo, o que corrobora com o grande número de fragmentos que possuem áreas menores que 1,0 ha. $\mathrm{A}$ média, mediana e moda do índice de forma das diferentes classes de cobertura do solo são na maioria considerados aqui de grau de pressão 1 e pouco variam.

\section{Parque Nacional do Superagui}

A delimitação realizada para a área de ocupação do Parque totalizou 34.453,36 ha. A matriz da paisagem dessa UC foi definida pela classe de vegetação nativa, a qual representou 92,86\% de área de cobertura do solo. A porosidade da matriz do Parque foi representada pela presença de 894 fragmentos. Estimando-se a sua densidade sem considerar sua localização, seu tamanho e forma, são 2,54 fragmentos a cada 100 ha. A porosidade, portanto, é considerada média.

A maioria dos fragmentos $(80,98 \%)$ apresentou área menor que 1,0 ha. Apenas 22 fragmentos $(2,46 \%)$ possuem área maior que 10 há: são 10 (dez) grandes fragmentos de água, 6 (seis) de areia e 6 (seis) de solo descoberto. Os fragmentos de área urbanizada, cerca de 6,50\%, são formados por comunidades caiçaras que residem no Parque.

Em relação às classes de perímetro, 60,29\% dos fragmentos possuem índice de forma menor que 1,5 de grau de pressão 1 e 25,50\% possuem índice entre 1,5 e 2,0 de grau de pressão 2, sendo a maioria de solo descoberto e de água. Índices maiores que 2,0 (grau de pressão 3) corresponderam a 14,21\% e são, na maioria, de solo descoberto e de água.

A predominância de fragmentos de água e de solo descoberto pode ser devido ao fato do PN ser formado por duas grandes ilhas (do Superagui e das Peças), duas pequenas ilhas (Pinheiro e Pinheirinho) e ainda por uma porção de continente. Os fragmentos de água são de origem natural, assim como alguns fragmentos classificados como solo descoberto, os quais podem ser áreas de restinga esparsa e até mesmo formações de cordões e intercordões.

Os cálculos da média, mediana e moda do índice de forma dos fragmentos quase não ultrapassaram o valor de 1,5, considerado de grau de pressão 1 , o que menos impacto tem sobre a matriz. As classes que apresentaram a maior média e mediana foram justamente as classes de água e areia, que podem formar faixas que acompanham o contorno das Ilhas.

A estrutura da paisagem do Parque, formado por uma matriz de vegetação nativa, fragmentos de água e solo descoberto (caracterizado por restinga esparsa) e alguns fragmentos de área urbana (que caracterizam a zona de uso intensivo no plano de manejo de uma UC de proteção integral), retrata o que se pressupõe como características de um Parque Nacional. Segundo o SNUC, é uma área de ecossistemas naturais de grande relevância ecológica e beleza cênica, que possibilita a realização de pesquisas científicas e o desenvolvimento de atividades de educação e interpretação ambiental, de recreação e de turismo ecológico (BRASIL, 2000).

Ainda que não seja permitida a permanência de comunidades humanas em uma UC de Proteção Integral (BRASIL, 2000), os parques brasileiros não retratam tal realidade. Os fragmentos de áreas urbanas no Parque Nacional do Superagui são regiões ocupadas por comunidades humanas que residem no Parque. Vivekananda (2001) realizou um estudo sobre essas comunidades e verificou, em entrevistas, que a criação do Parque não significou alteração alguma na rotina das pessoas, pois a agricultura de subsistência e a economia baseada na extração de palmito, caxeta e samambaia deixaram de ser a atividade econômica principal dez anos antes da criação do Parque. Trata-se de um fato importante, uma 
vez que a autora verificou um aumento na área de vegetação nativa em função da diminuição das áreas agrícolas. Entretanto, a extração de recursos naturais, seja para subsistência, seja para fins econômicos, ainda existe e é impactante e conflitante com o objetivo de conservação do Parque (VIVEKANANDA, 2001).

Área de Proteção Ambiental Estadual de Guaraqueçaba

Com o mesmo objetivo da APA Federal, a APA Estadual de Guaraqueçaba difere em seus limites da APA Federal por poucos hectares. A área delimitada para essa UC resultou em 229.788,83 ha. A sua matriz é a vegetação nativa, cobrindo $82,09 \%$ da área. Essa matriz tem sua porosidade definida pela presença de 8.117 fragmentos. Estimando-se a densidade de fragmentos, não considerando suas localizações, tamanho e forma, são 3,53 fragmentos a cada 100 ha. A porosidade é considerada média.

Quase metade dos fragmentos (49\%) é de vegetação alterada, seguida por $35,70 \%$ de solo descoberto. A maioria dos fragmentos $(72,55 \%)$ possui área menor que 1,0 ha, e cerca de $23,78 \%$ possuem de 1,0 a 10 ha. Apenas 13 (treze) fragmentos apresentaram área maior que 100 ha.

O índice de forma, distribuído nas classes de perímetro, enquadram $74,94 \%$ dos fragmentos com índice menor que 1,5 (grau de pressão 1) e 19,02\% entre 1,5 e 2,0 (grau de pressão 2). A minoria dos fragmentos $(6,04 \%)$ possui índice maior que 2,0, correspondente ao grau de pressão 3, ou seja, são os fragmentos que maior pressão exercem sobre a matriz de vegetação nativa. Desses fragmentos de grau de pressão 3, a maioria é de vegetação alterada.

As médias do índice de forma dos fragmentos são aproximadas para as diferentes classes de cobertura do solo. A média para as classes de água, areia e área urbanizada apresentou índice de forma de grau de pressão 2. A mediana e a moda para todas as classes de cobertura do solo foram menores que 1,5 , apresentando grau de pressão 1 .

Reserva Particular do Patrimônio Natural de Salto Morato

A Reserva Particular de Patrimônio Natural de Salto Morato foi criada pela Portaria 132/1994-N (BRASIL, 1994). Propriedade da Fundação O Boticário de Proteção à Natureza (FBPN), tem como objetivos a proteção de amostra da Floresta Atlântica, a proteção de belezas cênicas, a promoção de pesquisa científica, a realização de atividades de educação ambiental e de recreação em contato com a natureza e a realização de cursos de capacitação (FBPN, 2008).

O contorno definido para essa UC de uso sustentável resultou numa área de 885,51 ha. A sua matriz foi definida como sendo a vegetação nativa, a cobertura do solo que ocupa a maior área $(98,62 \%)$ dessa paisagem. A porosidade dessa matriz foi definida pela presença de 6 (seis) fragmentos. Estimandose a densidade de fragmentos, não considerando suas localizações, tamanho e forma, são 0,68 fragmentos a cada 100 ha. A porosidade é considerada baixa.

Foram encontrados 6 (seis) fragmentos, sendo 50\% de vegetação alterada e 50\% de área urbanizada. Cerca de $50 \%$ possuem menos de 1,0 ha e $50 \%$ mais de 1,0 ha. Os fragmentos de vegetação alterada podem se constituir em áreas de floresta em regeneração, e os fragmentos de área urbanizada correspondem à área construída para sede das atividades da RPPN.

Cerca de $50 \%$ dos fragmentos possuem o índice de forma menor que 1,5, considerado de grau de pressão 1, e 50\% apresentam índice maior que 1,5. A partir do índice de forma dos fragmentos, verificouse que os de área urbanizada são os que apresentam maiores irregularidades em sua forma, apresentando a maior média e mediana 2,02 e 2,22, respectivamente, e apresentando também o maior grau de pressão (3). Devido ao pequeno número de fragmentos, a moda não se mostrou representativa.

Reserva Particular do Patrimônio Natural Águas Belas

A Reserva Particular de Patrimônio Natural Águas Belas foi criada pela Portaria do Instituto Ambiental do Paraná (IAP) no 184 , de 2 de setembro de 2004. Propriedade da Sociedade de Pesquisa em Vida Selvagem e Educação Ambiental (SPVS), tem como objetivo a conservação de um significativo remanescente de Floresta Atlântica (SPVS, 2008).

A delimitação da área da RPPN Águas Belas totalizou 591,70 ha. A matriz dessa UC é a classe de cobertura do solo de vegetação nativa, que cobre $96,39 \%$ da área. Áreas urbanizadas representam $3,56 \%$ e vegetação alterada $0,05 \%$. 
A porosidade dessa matriz foi definida pela presença de apenas 5 (cinco) fragmentos. Estimando-se a densidade de fragmentos, não considerando suas localizações, tamanho e forma, são 0,85 fragmentos a cada 100 ha. A porosidade é considerada baixa.

Em relação às classes de área dos fragmentos, cerca de $80 \%$ possuem área menor que 1,0 ha, e $20 \%$ maior que $1,0 \mathrm{ha}$, sendo que esta última classe é representada por apenas um fragmento de área urbanizada. Quanto ao índice de forma dos fragmentos, $80 \%$ possuem índice menor que 1,5 e $20 \%$ índice maior que 1,5, este último constituído por apenas um fragmento de área urbanizada.

A média e mediana do índice de forma foi 2,04 para área urbanizada, considerada de grau de pressão 3. Os fragmentos de vegetação alterada apresentaram a média e mediana de 1,13 , de grau de pressão 1. A moda não foi analisada, devido ao pequeno número de fragmentos - apenas 4 (quatro).

Devido ao pequeno número de fragmentos e, consequentemente, à baixa porosidade da matriz, os atributos obtidos para essa UC são mais bem analisados em conjunto. Pelo fato de a área da RPPN Águas Belas ter o histórico de uma fazenda, tais fragmentos são os remanescentes da propriedade. As áreas de vegetação alterada podem ter sido áreas de pasto e agricultura e hoje são áreas de vegetação em regeneração, que podem até mesmo fazer parte dos experimentos com regeneração de áreas degradadas e crédito de carbono, realizados pela SPVS. Assim, a proteção dessa área, instituída como UC, faz com que os fragmentos de vegetação alterada e até mesmo de áreas urbanas sejam de caráter transitório.

\section{Mosaico de unidades de conservação do litoral norte do Paraná}

A área é formada por 6 (seis) Unidades de Conservação (Figura 2). Destas, 4 (quatro) são de Uso Sustentável e 2 (duas) de Proteção Integral, ocupando 310.419,43 ha. A vegetação nativa foi a classe de cobertura do solo com maior área de ocupação, totalizando $243.968,23$ ha, cerca de $79 \%$ da área. A água representou $12,36 \%$ da área, áreas urbanizadas $4,29 \%$, vegetação alterada $2,98 \%$, solo descoberto $1,50 \%$ e areia $0,27 \%$ (Figura 3 ).

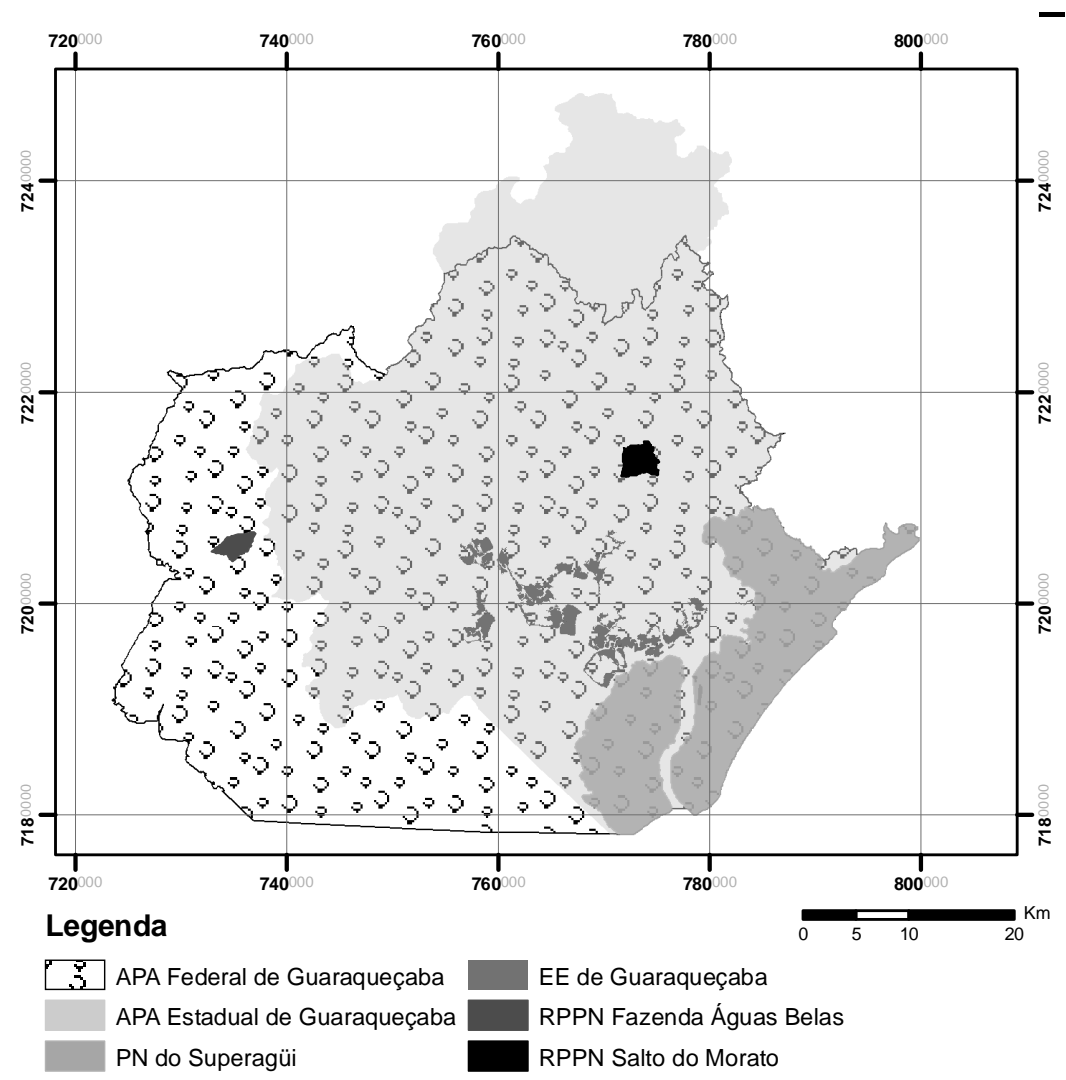

Figura 2. Delimitação das Unidades de Conservação da área de estudo.

Figure 2. Limits of the Conservation Units in study area. 


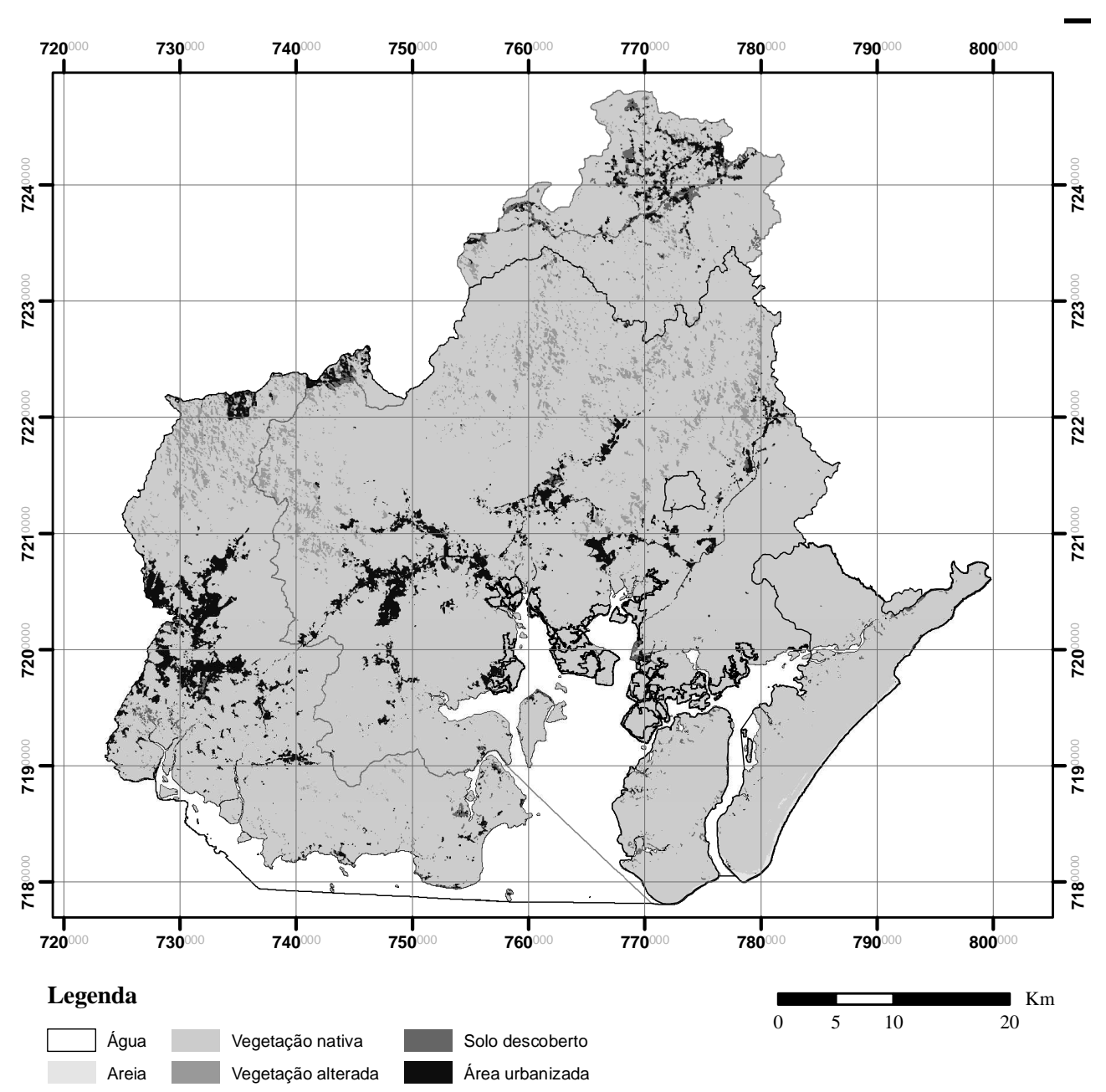

Figura 3. Classes de cobertura do solo e limites das Unidades de Conservação da área de estudo. Figure 3. Cover soil classes and limits of the Conservation Units in study area.

Quando analisadas em conjunto, todas as UCs possuem a maior área de cobertura do solo representada pela classe de vegetação nativa. As áreas urbanizadas e de vegetação alterada se sobressaem nas APAs, cujo objetivo, entre outros, é conciliar a conservação da natureza com a ocupação pelas comunidades caiçaras. As APAs possuem as maiores áreas cobertas por vegetação alterada, uma vez que essas UCs são formadas por propriedades privadas com as mais diversas coberturas do solo, bem como por comunidades caiçaras que causam pressão sobre os recursos naturais. A quantificação das variáveis analisadas em cada Unidade de Conservação é apresentada na tabela 1.

\section{Matriz do mosaico}

A matriz da área de estudo foi representada pela vegetação nativa, que representou 78,59\%, ou seja, mais de $50 \%$ da área de cobertura do solo, segundo metodologia de Forman; Godron (1986). A matriz de todas as UCs, bem como a da área total, foi representada pela mesma classe de cobertura do solo, a vegetação nativa. Segundo Forman; Godron (1986), a matriz é o pano de fundo da paisagem, controlando sua dinâmica e afetando os fragmentos e corredores. Considerando que a área da APA Federal e das demais UCs possuem a mesma matriz da paisagem, pode-se dizer que os fluxos de matéria, energia e espécies ocorrem de forma contínua na matriz de vegetação nativa, uma vez que a matriz controla a dinâmica da paisagem, o que é vantajoso para a conservação dessa porção importante de Floresta Atlântica. 
Tabela 1. Quantificação das variáveis analisadas em cada Unidade de Conservação.

Table 1. Quantification of the analyzed variables in each Conservation Units.

\begin{tabular}{|c|c|c|c|c|c|c|c|c|}
\hline & & EE & $\begin{array}{l}\text { APA } \\
\text { FED }\end{array}$ & PN & $\begin{array}{l}\text { APA } \\
\text { EST }\end{array}$ & $\begin{array}{c}\text { RPPN } \\
\text { SM }\end{array}$ & $\begin{array}{c}\text { RPPN } \\
\text { AB }\end{array}$ & $\begin{array}{c}\text { Área } \\
\text { total }\end{array}$ \\
\hline \multirow{6}{*}{$\begin{array}{l}\text { Classes de } \\
\text { cobertura do solo } \\
(\%)\end{array}$} & Vegetação nativa & 97,98 & 77,94 & 92,86 & 82,08 & 98,63 & 96,39 & 78,60 \\
\hline & Água & 0,87 & 13,64 & 3,22 & 9,72 & 0,00 & 0,00 & 12,36 \\
\hline & Área urbanizada & 0,01 & 4,16 & 0,09 & 3,31 & 0,82 & 3,56 & 4,29 \\
\hline & Areia & 0,00 & 0,30 & 2,40 & 0,37 & 0,00 & 0,00 & 0,27 \\
\hline & Solo descoberto & 1,05 & 1,07 & 1,41 & 1,47 & 0,00 & 0,00 & 1,50 \\
\hline & Vegetação alterada & 0,09 & 2,89 & 0,01 & 3,05 & 0,55 & 0,05 & 2,98 \\
\hline \multirow{2}{*}{$\begin{array}{l}\text { Estrutura da } \\
\text { paisagem }(\%)\end{array}$} & Matriz & 97,98 & 77,94 & 92,86 & 82,08 & 98,63 & 96,39 & 78,60 \\
\hline & Fragmentos & 2,02 & 22,06 & 7,14 & 17,92 & 1,37 & 3,61 & 21,40 \\
\hline \multirow{2}{*}{$\begin{array}{l}\text { Porosidade da } \\
\text { matriz }\end{array}$} & $\mathrm{N}^{\circ}$ fragmentos/100 ha & 5,38 & 3,28 & 2,59 & 3,53 & 0,68 & 0,85 & 3,72 \\
\hline & Classes & alta & média & média & média & baixa & baixa & média \\
\hline \multirow{5}{*}{$\begin{array}{l}\text { Fragmentos em } \\
\text { cada classe de } \\
\text { cobertura do solo } \\
(\%)\end{array}$} & Água & 31,46 & 2,26 & 45,97 & 1,87 & 0,00 & 0,00 & 1,81 \\
\hline & Área urbanizada & 2,25 & 14,18 & 6,49 & 12,52 & 50,00 & 40,00 & 14,02 \\
\hline & Areia & 45,69 & 0,80 & 8,28 & 0,91 & 0,00 & 0,00 & 0,64 \\
\hline & Solo descoberto & 0,00 & 38,91 & 37,47 & 35,70 & 0,00 & 0,00 & 38,76 \\
\hline & Vegetação alterada & 20,60 & 43,85 & 1,79 & 49,00 & 50,00 & 60,00 & 44,77 \\
\hline \multirow{3}{*}{$\begin{array}{l}\text { Classes de } \\
\text { perímetro dos } \\
\text { fragmentos }(\%)\end{array}$} & $<1,5$ & 44,57 & 74,93 & 60,29 & 74,94 & 50,00 & 80,00 & 74,77 \\
\hline & 1,5 a 2,0 & 26,59 & 18,46 & 25,50 & 19,02 & 0,00 & 0,00 & 18,85 \\
\hline & $>2,0$ & 28,84 & 6,61 & 14,21 & 6,04 & 50,00 & 20,00 & 6,38 \\
\hline \multirow{4}{*}{$\begin{array}{l}\text { Classes de área } \\
\text { (ha) dos } \\
\text { fragmentos }(\%)\end{array}$} & $<1,0$ ha & 91,76 & 73,82 & 80,98 & 72,55 & 50,00 & 80,00 & 73,60 \\
\hline & 1,0 a 10 ha & 8,24 & 22,25 & 16,55 & 23,78 & 50,00 & 0,00 & 22,79 \\
\hline & 10 a 100 ha & 0,00 & 3,72 & 1,90 & 3,51 & 0,00 & 20,00 & 3,41 \\
\hline & $>100$ ha & 0,00 & 0,21 & 0,56 & 0,16 & 0,00 & 0,00 & 0,20 \\
\hline \multirow{5}{*}{$\begin{array}{l}\text { Média do índice } \\
\text { de forma dos } \\
\text { fragmentos }\end{array}$} & Água & 3,73 & 1,65 & 1,76 & 1,73 & $*$ & $*$ & 1,65 \\
\hline & Área urbanizada & 2,33 & 1,54 & 1,33 & 1,56 & 2,02 & 2,04 & 1,55 \\
\hline & Areia & $*$ & 1,58 & 1,59 & 1,58 & $*$ & $*$ & 1,58 \\
\hline & Solo descoberto & 1,71 & 1,34 & 1,45 & 1,34 & $*$ & $*$ & 1,35 \\
\hline & Vegetação alterada & 1,33 & 1,39 & 1,24 & 1,37 & 1,13 & 1,13 & 1,28 \\
\hline \multirow{5}{*}{$\begin{array}{l}\text { Mediana do índice } \\
\text { de forma dos } \\
\text { fragmentos }\end{array}$} & Água & 2,37 & 1,39 & 1,51 & 1,43 & $*$ & $*$ & 1,39 \\
\hline & Área urbanizada & 2,28 & 1,38 & 1,20 & 1,38 & 2,22 & 2,04 & 1,38 \\
\hline & Areia & $*$ & 1,20 & 1,20 & 1,20 & * & $*$ & 1,20 \\
\hline & Solo descoberto & 1,55 & 1,20 & 1,38 & 1,20 & $*$ & $*$ & 1,20 \\
\hline & Vegetação alterada & 1,23 & 1,30 & 1,20 & 1,28 & 1,41 & 1,13 & 1,38 \\
\hline \multirow{5}{*}{$\begin{array}{l}\text { Moda do índice de } \\
\text { forma dos } \\
\text { fragmentos }\end{array}$} & Água & 1,40 & 1,13 & 1,37 & 1,36 & $*$ & $*$ & 1,13 \\
\hline & Área urbanizada & 2,28 & 1,20 & 1,13 & 1,20 & $* *$ & $* *$ & 1,20 \\
\hline & Areia & $*$ & 1,13 & 1,13 & 1,13 & * & * & 1,13 \\
\hline & Solo descoberto & 1,13 & 1,13 & 1,20 & 1,13 & $*$ & $*$ & 1,13 \\
\hline & Vegetação alterada & 1,13 & 1,13 & 1,13 & 1,13 & $* *$ & $* *$ & 1,13 \\
\hline
\end{tabular}

Ârea total: Área total de estudo; EE: Estação Ecológica de Guaraqueçaba; APA FED: Área de Proteção Ambiental Federal de Guaraqueçaba; PN: Parque Nacional do Superagui; APA EST: Área de Proteção Ambiental Estadual de Guaraqueçaba; RPPN SM: Reserva Particular do Patrimônio Natural Salto Morato; RPPN AB: Reserva Particular do Patrimônio Natural Águas Belas; *: não apresenta a referida classe; **: valor não avaliado.

Quando todas as UCs que se sobrepõem, ou compõem o mosaico de uma região, possuem a mesma matriz, a dinâmica dessa paisagem é única. A área de estudo, apesar de dividida, seja pelas UCs ou pelas diferentes coberturas do solo dadas às propriedades, possui em sua matriz de vegetação nativa o controle da dinâmica da paisagem. Os fluxos de energia, matéria e espécies percorrerão a matriz, que é 
única na área de estudo: a vegetação nativa. Esse fato é extremamente importante e eficaz para o objetivo de um mosaico de áreas protegidas. Sendo a matriz a principal responsável pela conservação da paisagem, e sendo a vegetação nativa a matriz do mosaico, então os processos ecológicos e, consequentemente, a conservação dessa paisagem, são garantidos.

Entre as UCs que possuem maior área de matriz estão as RPPNs Salto Morato $(98,62 \%)$ e Águas Belas $(96,39 \%)$ e a EE de Guaraqueçaba $(97,99 \%)$. A EE, entre as UCs aqui analisadas, é a categoria de proteção com maiores restrições de uso, sendo permitida apenas a pesquisa científica de baixo impacto e sob autorização prévia (BRASIL, 2000). A representatividade da matriz de vegetação nativa da EE pode ser um indício de que a área está protegida, não somente pela lei, mas também pela conservação de seus ecossistemas. As RPPNs, por sua vez, apesar de serem UCs de Uso Sustentável, são áreas destinadas à conservação por particulares, que por vontade própria lavram em caráter perpétuo a proteção de suas terras. A essência dessa categoria de proteção, por si só, pode explicar serem elas as UCs de maior área de matriz de vegetação nativa.

A matriz, entretanto, não é contínua, mas perfurada pela presença de fragmentos de área que possuem coberturas do solo que diferem da matriz. A porosidade de uma matriz, que pode ser mensurada relacionando-se o número, tamanho e perímetro ou forma dos fragmentos (FORMAN, 1995), foi definida pela presença de 11.552 fragmentos. Pode-se dizer que é uma matriz porosa, ou seja, que possui fragmentos espalhados por toda sua área. Estimando-se a densidade de fragmentos, encontraram-se 3,72 fragmentos a cada 100 ha, uma porosidade considerada média.

Assim como a área total de estudo, a APA Estadual, a APA Federal e o PN apresentaram porosidade média, com valores estimados em 3,28, 3,53 e 2,59 fragmentos a cada 100 ha, respectivamente. As RPPNs apresentaram porosidade baixa. A única UC que apresentou porosidade alta, com 5,38 fragmentos a cada 100 ha, foi a EE. Ela, entretanto, é uma área formada por porções distintas de mangue, cujos fragmentos são em maioria de água e solo descoberto, os quais podem ser considerados de origem natural, pouco interferindo na matriz de vegetação nativa, e sim compondo a paisagem característica dessa UC, formada por 14 áreas distintas de mangue.

Fragmentos do mosaico

Os fragmentos são formados pelas classes de vegetação alterada, solo descoberto, áreas urbanizadas, água e areia. Apesar de os fragmentos representarem $21,40 \%$ da área de estudo, e destes $57,74 \%$ serem áreas naturais com presença de água, a porosidade da matriz se mostra importante pela presença de 11.552 fragmentos.

Ainda que a matriz de vegetação nativa controle a dinâmica da paisagem, as áreas naturais tendem a ser suprimidas pelas atividades humanas, como a própria história da humanidade indica. Pode ocorrer o efeito de borda inverso, no qual os fragmentos antropizados, sejam de áreas urbanizadas, vegetação alterada ou até mesmo solo descoberto, vão pressionar a matriz e aumentar suas áreas de ocupação. Pequenos fragmentos antropizados espalhados pela matriz de vegetação nativa aumentam a área da matriz suscetível a interferências, aqui consideradas negativas.

Forman (1995) considera que os fragmentos têm origem em distúrbios que podem ser eventos únicos ou repetidos, com as mudanças que ocorrem no meio podendo ser maiores ou menores, dependendo da origem e causa do fragmento. Fragmentos regenerados e de perturbações mudam rapidamente, refletindo a taxa de sucessão e dispersão quando eles convergem similares à vegetação adjacente. Entretanto, os fragmentos encontrados para a área de estudo são fragmentos de eventos repetidos e permanentes, que tendem a aumentar a pressão sobre a matriz. São fragmentos que têm em sua origem as atividades humanas. São constituídos de áreas urbanizadas, vegetação alterada ou solo descoberto, encontrando no fator extrativismo um grande aliado. Devido a sua origem e causa, são fragmentos que podem ser estáveis (permanecem com a mesma área) ou instáveis (aumentam constantemente sua área, mas raramente têm sua área diminuída).

Segundo Forman (1995), quando 40\% da área forem fragmentos e 60\% matriz, é iniciado o processo de formação de corredores, uma vez que os fragmentos tendem a se unir dessa forma. Numa matriz de vegetação natural, os fragmentos antrópicos de áreas urbanizadas, vegetação alterada e solo descoberto exercem grande pressão sobre a vegetação nativa e tendem a se juntar, podendo formar extensos corredores antrópicos, como estradas. Inicia-se e acentua-se o processo de deterioração da qualidade do ambiente, fato extremamente negativo à conservação da natureza. 
Um ponto importante de ser abordado é o fato de que muitas vezes, em estudos com imagens de satélite, áreas consideradas de vegetação nativa podem estar comprometidas pelo corte seletivo ou ainda pela síndrome da floresta vazia e das extinções ecológicas. Esses termos, utilizados por Fernandez (2000), dizem respeito aos números (na casa dos milhões) sobre a caça legal em um porto na Amazônia Peruana, alertando sobre a escassez de espécies de grandes animais em várias áreas da Amazônia, mesmo onde a fragmentação ainda não está tão avançada. Uma extinção ecológica ocorre quando espécies, embora ainda sobrevivam na região, têm densidades populacionais tão baixas que já não conseguem mais exercer os papéis ecológicos que antes desempenhavam no ecossistema. Devido à escala utilizada nesta pesquisa, pode ter ocorrido esse fato em algumas áreas de floresta natural onde, na realidade, pode ser constatada uma fragmentação ainda maior, se realizado um estudo com uma escala maior e com verificações em campo.

Os fragmentos variam em tamanho, de menos de 1,0 ha a fragmentos com mais de 100 ha. A maioria $(73,60 \%)$ dos fragmentos da área total de estudo apresentou menos de 1,0 há, 22,79\% apresentaram entre 1,0 e 10 há, $3,41 \%$ entre 10 e 100 ha e apenas $0,20 \%$ mais de 100 ha.

Os valores obtidos para a área total de estudo corroboraram os valores encontrados para a maioria das UCs. Predominam os fragmentos com menos de 1,0 ha. A presença de um grande número de pequenos fragmentos espalhados pela área de estudo retrata a porosidade e consequentemente, a exposição da área a interferências antrópicas. Se os fragmentos de áreas urbanizadas, de vegetação alterada e de solo descoberto fossem maiores, entretanto concentrados em determinadas regiões, então a área da matriz afetada pelos fragmentos seria menor. $\mathrm{O}$ efeito de borda inverso seria menor, ou seja, a borda do fragmento antrópico é que pressiona a matriz de vegetação natural e tende a aumentar sua área. Tendo um menor número de fragmentos, entretanto de maiores tamanho, seriam menos bordas a pressionar e alterar a matriz.

Os fragmentos possuem perímetros que variam de $120 \mathrm{~m}$ a fragmentos com mais de $120.000 \mathrm{~m}$ de perímetro. A maioria dos fragmentos $(74,83 \%)$ da área total de estudo apresentou índice de forma menor que 1,5 , o qual representa o grau de pressão 1 , ou seja, que exerce menor pressão sobre a matriz. Cerca de $18,87 \%$ apresentaram entre 1,5 e 2,0 de grau de pressão 2 ; e 6,30\% maior que 2,0, com grau de pressão 3 .

Como ocorreu com a área total de estudo, as UCs apresentaram o mesmo padrão de distribuição do número de fragmentos pelas classes de perímetro e consequentemente pelas classes de grau de pressão. Fragmentos que possuem menores índices de forma, ou seja, que tenham suas formas mais regulares, e que por consequência exerçam menor pressão sobre a matriz, são mais vantajosos para a conservação da área de estudo, bem como para as UCs.

\section{Legislação das UCs e do mosaico}

As UCs existentes no litoral norte do Estado do Paraná estão descritas na tabela 2, com seus decretos de criação, área de ocupação e características gerais.

Observa-se na tabela 2 que as APAs possuem quase que o mesmo limite de área e seus objetivos se repetem. A APA Federal, criada primeiro, em 1985, por ser de âmbito federal, já suplanta a APA Estadual, que praticamente perde seu sentido. Interessante seria adicionar à área da APA Federal a porção de terra que não coincide com a APA Estadual e extinguir a APA Estadual. Essa medida já foi recomendada em estudo realizado por Auer (1995), no qual a autora destacou a sobreposição das APAs Federal e Estadual de Guaraqueçaba e recomendou a desconstituição da APA Estadual.

A EE e o PN são UCs importantes e representativas da biota regional, de Proteção Integral, e que têm como zona de amortecimento e proteção a APA Federal. Por apresentarem a mesma matriz da APA e as mesmas classes de cobertura do solo dos fragmentos, formam uma paisagem homogênea, ou uma unidade paisagística (BIONDI, 2005). O fato de as UCs possuírem as mesmas características de matriz faz com que elas contribuam para a funcionalidade do mosaico.

As RPPNs, apesar de serem UCs de Uso Sustentável, são também contribuintes ao funcionamento do mosaico. Ainda que o SNUC considere-as de Uso Sustentável, possuem as características e restrições de uso de uma UC de Proteção Integral, contribuindo tanto para a conservação quanto para a pesquisa científica e para a conscientização através da educação ambiental.

Auer (1995), na avaliação das UCs do estado do Paraná, classificou o PN do Superagui e a EE de Guaraqueçaba como UCs fundamentais, e as APAs como UCs acessórias, considerando estas dentro do contexto de um Sistema de UCs viáveis para a proteção da Floresta Ombrófila Densa no Estado. 
Tabela 2. Aspectos legais e caracterização das UCs da área de estudo.

Table 2. Legal and characterization of Conservation Units in study area.

\begin{tabular}{|c|c|c|c|c|}
\hline $\begin{array}{l}\text { Categoria de } \\
\text { Proteção }\end{array}$ & $\begin{array}{c}\text { Unidade de } \\
\text { Conservação }\end{array}$ & Criação & $\begin{array}{c}\text { Área } \\
\text { estimada }\end{array}$ & Características da área \\
\hline $\begin{array}{l}\text { Proteção } \\
\text { Integral }\end{array}$ & $\begin{array}{c}\text { Estação } \\
\text { Ecológica de } \\
\text { Guaraqueçaba }\end{array}$ & $\begin{array}{c}\text { Dec. } n^{\circ} .87 .222 \\
31 / 05 / 1982 \\
\text { (BRASIL, 1982) }\end{array}$ & $4.964,19$ ha & $\begin{array}{l}\text { Formada por porções descontínuas } \\
\text { de solo, grande parte coberta por } \\
\text { mangue. } \\
\text { Grande porção contínua de }\end{array}$ \\
\hline $\begin{array}{l}\text { Uso } \\
\text { Sustentável }\end{array}$ & $\begin{array}{l}\text { APA Federal de } \\
\text { Guaraqueçaba }\end{array}$ & $\begin{array}{c}\text { Dec. } n^{\circ} .90 .883 \\
31 / 01 / 1985 \\
\text { (BRASIL, 1985) }\end{array}$ & $280.919,40$ ha & $\begin{array}{l}\text { Floresta Atlântica, formada por } \\
\text { vegetação nativa (floresta, restinga } \\
\text { e mangue) e áreas antropizadas. } \\
\text { Um dos seus objetivos é proteger } \\
\text { o entorno da EE de Guaraqueçaba. } \\
\text { Área composta pelas Ilhas do }\end{array}$ \\
\hline $\begin{array}{l}\text { Proteção } \\
\text { Integral }\end{array}$ & $\begin{array}{c}\text { Parque Nacional } \\
\text { do Superagui }\end{array}$ & $\begin{array}{c}\text { Dec. } \mathrm{n}^{\circ} .97 .688 \\
\text { 25/04/1989 } \\
\text { (BRASIL, 1989) } \\
\text { Lei n'. } 9.513 \\
\text { 20/11/1997 } \\
\text { (BRASIL, 1997) }\end{array}$ & $34.453,36$ ha & $\begin{array}{l}\text { Superagui, das Peças, de Pinheiro } \\
\text { e Pinheirinho e uma porção do } \\
\text { continente. A vegetação nativa } \\
\text { predomina, entretanto ocorrem } \\
\text { áreas antropizadas, caracterizadas } \\
\text { pelas comunidades caiçaras } \\
\text { residentes no Parque. }\end{array}$ \\
\hline $\begin{array}{l}\text { Uso } \\
\text { Sustentável }\end{array}$ & $\begin{array}{c}\text { APA Estadual de } \\
\text { Guaraqueçaba }\end{array}$ & $\begin{array}{c}\text { Dec. Est. } \mathrm{n}^{\circ} .1 .228 \\
\text { 27/03/1992 } \\
\text { (BRASIL, 1992) }\end{array}$ & $229.460,46$ ha & $\begin{array}{c}\text { Grande porção contínua de } \\
\text { Floresta Atlântica, formada por } \\
\text { vegetação nativa (floresta, restinga } \\
\text { e mangue) e áreas antropizadas. } \\
\text { Difere da APA Federal em poucos } \\
\text { hectares e possui objetivos quase } \\
\text { idênticos. }\end{array}$ \\
\hline $\begin{array}{l}\text { Uso } \\
\text { Sustentável }\end{array}$ & $\begin{array}{l}\text { RPPN Salto } \\
\text { Morato }\end{array}$ & $\begin{array}{c}\text { Portaria } 132 \\
\text { 08/12/1994 } \\
\text { (BRASIL, 1994) }\end{array}$ & 885,51 ha & $\begin{array}{c}\text { Área transformada em UC pela } \\
\text { ONG FBPN. Área de vegetação } \\
\text { nativa com porções antropizadas e } \\
\text { de vegetação alterada. }\end{array}$ \\
\hline $\begin{array}{l}\text { Uso } \\
\text { Sustentável }\end{array}$ & $\begin{array}{l}\text { RPPN Águas } \\
\text { Belas }\end{array}$ & $\begin{array}{c}\text { Portaria } 184 \\
\text { 02/09/2004 } \\
\text { (PARANÁ, 2004) }\end{array}$ & 591,70 ha & $\begin{array}{l}\text { Área transformada em UC pela } \\
\text { ONG SPVS. Área de vegetação } \\
\text { nativa com porções antropizadas. }\end{array}$ \\
\hline
\end{tabular}

Segundo a International Union for Conservation of Nature (IUCN), as Protected Landscapes, categoria similar à APA, devem se relacionar com outras áreas protegidas (PHILLIPS, 2002). O mosaico de UCs, aqui representado por 6 (seis) unidades, atendem ao proposto pela IUCN: possuem duas pequenas reservas de proteção integral, o PN e a EE; as APAs Federal e Estadual funcionam como zona de amortecimento ao redor das áreas de proteção integral; as APAs são ainda o elo de ligação entre várias outras áreas protegidas, como as RPPNs; a área ajuda a criar o grande bloco de conservação da Floresta Atlântica no Brasil.

A criação dessas UCs e outras que possam surgir, seu adequado enquadramento nas diferentes categorias e seus planos de manejo elaborados são fatores que podem estar perfeitamente arranjados, entretanto nada do que está no papel (documentos) tem valor se não for corretamente aplicado. A grande quantidade de diplomas legais que incidem na região não garante sua integridade. Apenas sua aplicabilidade, eficácia jurídica e social garantem seu real valor (SPVS, 1992).

Por último, mas não menos importante, em 8 de maio de 2006, o MMA publicou a Portaria ${ }^{\circ}$ 150, que criou o Mosaico de Unidades de Conservação, abrangendo as unidades de conservação e suas zonas de amortecimento, localizadas no litoral sul do estado de São Paulo e no litoral do estado do Paraná (BRASIL, 2006). Entre essas UCs estão as 6 (seis) apresentadas neste trabalho e outras 28, totalizando 34 unidades distribuídas entre São Paulo e Paraná, nas mais diversas categorias de proteção.

É interessante que tais áreas não fazem parte do Projeto Corredor Central da Mata Atlântica do Brasil, grande projeto piloto apresentado e divulgado pelo MMA em 2006 (MMA, 2006), que abrange mais de 8,5 milhões de hectares, estendendo-se do estado do Espírito Santo à porção sul da Bahia. Entretanto a área faz parte do Projeto Corredor da Serra do Mar, o qual cobre cerca de 12,6 milhões de 
hectares e estende-se do estado do Rio de Janeiro ao Paraná. Segundo a Aliança para Conservação da Mata Atlântica (2008), o Corredor de Biodiversidade da Serra do Mar pode ser comparado a um mosaico de diferentes coberturas da terra, que integra parques e reservas naturais, áreas de cultivo e pastagem, centros urbanos e atividades industriais.

Zona de amortecimento das UCs

Uma discussão que se faz presente nas reuniões mundiais a respeito da proteção de áreas naturais é a inclusão de áreas marinhas nos sistemas de conservação. Tal discussão é pertinente quando se verifica que pouquíssimas reservas naturais incluem porções marinhas em seus limites. Esse fato é comprovado quando se observa a zona de amortecimento do PN do Superagui. Considerando-se $10 \mathrm{~km}$ de raio (como estabelecido pelo CONAMA) de zona de amortecimento do PN, cerca de $49 \%$ da área encontram-se fora da área da APA Federal de Guaraqueçaba. Grande parte desse percentual é de áreas marinhas. Um dos pressupostos de uma APA é servir de zona de amortecimento para as UCs de Proteção Integral, mas o PN foi criado depois da APA Federal de Guaraqueçaba.

As classes de cobertura do solo de vegetação nativa são as que representam a maior área de ocupação da zona de amortecimento da EE, cerca de 69\%. São as classes que representam a matriz da EE, bem como da área total de estudo. As áreas urbanizadas, que causam maior impacto às áreas naturais, representam apenas 3,59\% de ocupação ao redor da EE. A APA Federal tem como um de seus objetivos principais, conforme seu decreto de criação, servir de zona de amortecimento à EE, entretanto não atinge seu objetivo na plenitude. Cerca de 7\% da zona de amortecimento da EE estão fora dos limites da APA, sendo formados de áreas marinhas, o que evidencia uma falha do sistema (mosaico) ao não oferecer atenção e proteção às áreas marinhas. A APA Federal de Guaraqueçaba foi criada após a EE, portanto poderia e deveria incluir em seus limites toda a zona de amortecimento da EE.

\section{Funcionalidade do mosaico de UCs do litoral norte do Paraná}

A área de estudo é formada por 6 (seis) UCs de diferentes categorias de manejo, objetivos e tamanhos de área. Essa diversidade de áreas com categorias de manejo distintas, em uma mesma região, é fundamental para que uma maior quantidade de diferentes ecossistemas e espécies seja protegida. Segundo exemplificam e ilustram Dudley; Parish (2006), uma paisagem somente terá sua biodiversidade protegida quando contiver várias áreas sob proteção, de diferentes restrições de uso, em uma mesma região.

Essas 6 (seis) UCs formam um mosaico de áreas protegidas, e assim, possuindo a mesma classe de cobertura do solo para representar a matriz da paisagem do mosaico, os fluxos de matéria, energia e principalmente de espécies na paisagem são garantidos, uma vez que a matriz detém a dinâmica da paisagem. Sendo essa matriz de vegetação nativa, torna-se ainda mais importante, por tratar-se de áreas destinadas à conservação da natureza.

Os fragmentos que interrompem a matriz são áreas antropizadas, que exercem pressão sobre a matriz de vegetação nativa. Portanto, são perigosos por impactar a matriz. Entretanto até mesmo áreas antropizadas podem ser importantes para se manter o equilíbrio biótico de uma região, uma vez que já fazem parte da paisagem.

As áreas marinhas não são incluídas nas delimitações da UCs, o que representa uma falha na legislação, uma vez que fazem parte da zona de amortecimento de UCs de proteção integral, como o Parque Nacional do Superagui e a Estação Ecológica de Guaraqueçaba. Ressalta-se ainda que essas áreas marinhas exercem influência direta no mangue, objeto de proteção das UCs citadas, como o próprio nome sugere: Formação Pioneira de Influência Fluviomarinha.

\section{CONCLUSÕES}

O uso da imagem Landsat 5 TM, de resolução espacial de $30 \mathrm{~m}$, se mostrou satisfatória para classificar a cobertura do solo e delimitar as Unidades de Conservação presentes na região de Guaraqueçaba, litoral norte do estado do Paraná.

A caracterização e análise da estrutura da paisagem, através dos componentes matriz e fragmentos da área formada pelas Unidades de Conservação, serviram de base para a análise da funcionalidade do mosaico de Unidades de Conservação do litoral norte do estado do Paraná. 
O mosaico de Unidades de Conservação, aqui representado por 6 (seis) Unidades, pode ser considerado um mosaico funcional do ponto de vista da estrutura da paisagem e da legislação vigente, pelas seguintes razões:

- As UCs possuem a mesma classe de cobertura do solo para representar sua matriz, a classe de vegetação nativa, o que traz vantagens do ponto de vista da estrutura da paisagem, uma vez que a matriz detém a dinâmica, bem como a funcionalidade e os fluxos de matéria, energia e espécies da paisagem.

- As UCs possuem as mesmas classes de cobertura do solo para representar seus fragmentos: áreas urbanizadas, solo descoberto, vegetação alterada, areia e água.

- A área de estudo possui duas pequenas reservas de proteção integral, o Parque Nacional do Superagui e a Estação Ecológica de Guaraqueçaba, as quais são protegidas pelas Áreas de Proteção Ambiental Federal de Guaraqueçaba e Estadual de Guaraqueçaba, que funcionam como zona de amortecimento ao redor das áreas de proteção integral.

- A área de estudo possui duas grandes reservas, a APA Federal e a APA Estadual de Guaraqueçaba, as quais são o elo entre várias outras áreas protegidas, além das de proteção integral, as Reservas Particulares do Patrimônio Natural de Águas Belas e de Salto Morato.

- As UCs em conjunto ajudam a criar o grande bloco de conservação da Floresta Atlântica no Brasil.

A área das APAs Federal de Guaraqueçaba e Estadual de Guaraqueçaba não contemplam a totalidade das zonas de amortecimento do Parque Nacional do Superagui e da Estação Ecológica de Guaraqueçaba, pois não protegem as áreas marinhas ao redor dessas Unidades de Conservação.

Ainda que criadas de forma espaçada e quase que independente, as UCs presentes no litoral norte do estado do Paraná representam um mosaico de áreas protegidas em que cada UC, com seu objetivo específico de criação, contempla o objetivo maior de, a partir de mecanismos legais, preservar o último remanescente da floresta (símbolo do país) de maior diversidade biológica do mundo: a Floresta Atlântica.

Independentemente de seu objetivo específico de proteção - seja o mangue, como é o caso da EE, sejam as Ilhas do Superagui e das Peças, verdadeiros viveiros naturais de extrema biodiversidade, ou os centros de educação ambiental e de pesquisa das RPPNS, ou ainda as APAs, que muitas vezes são vistas pela comunidade local ou por empreendedores como retardadoras do progresso -, a estrutura da paisagem dessas UCs mostra que cada qual no seu objetivo específico acaba tendo um papel fundamental para a conservação da área, que ainda se comunicará com uma série de outros mosaicos de UCs do litoral brasileiro, garantindo não apenas a conservação local, mas a continuidade dos processos evolutivos da Floresta Atlântica.

\section{REFERÊNCIAS}

ALIANÇA PARA A CONSERVAÇÃO DA MATA ATLÂNTICA. Corredores de biodiversidade da Mata Atlântica. Disponível em: <http://www.corredores.org.br/> Acesso em: jan 2008.

AMATO, F; SUGAMOTO, M. L.; GRANDO, E, T. Evolução da cobertura florestal na APA de Guaraqueçaba entre 1989 e 1999. In: CONGRESSO BRASILEIRO DE UNIDADES DE CONSERVAÇÃO, 2., 2000, Campo Grande. Anais... Campo Grande: Rede Nacional Pró-Unidades de Conservação, Fundação O Boticário de Proteção à Natureza, 2000b. 2 v. p. 349-355.

AUER, A. M. Avaliação das unidades de conservação do estado do Paraná e da viabilidade de um Sistema de Unidades de Conservação. Dissertação (Mestrado em Engenharia Florestal) - Setor de Ciências Agrárias, Universidade Federal do Paraná, Curitiba, 1995.

BENNETT, G.; MULONGOY, K. J. Review of experience with ecological networks, corridors and buffer zones. Montreal: Secretariat of the Convention on Biological Diversity, 2006. (Thechnical Series, n. 23).

BENSUSAN, N. Conservação da biodiversidade em áreas protegidas. Rio de Janeiro: FGV, 2006.

BIONDI, D; LEAL, C. T. Análise da capacidade paisagística do Parque Estadual de Vila Velha - PR. In: CONGRESSO BRASILEIRO DE UNIDADES DE CONSERVAÇÃO, 3, 2002, Fortaleza. Anais... 
Fortaleza: Rede Nacional Pró-Unidades de Conservação, Fundação O Boticário de Proteção à Natureza, Associação Caatinga, 2002. p. 359-367.

BIONDI, D. Disciplina de estudos da paisagem - Curso de Pós-graduação em Engenharia Florestal da UFPR. Curitiba, 2005. Notas de aula.

BRASIL. Decreto n. 87.222, de 31 de maio de 1982. Institui a Estação Ecológica de Guaraqueçaba. Diário Oficial da União, Brasília, 31 de maio de 1982.

Decreto n. 90.883, de 31 de janeiro de 1985. Dispõe sobre a implantação da Área de Proteção Ambiental de Guaraqueçaba. Diário Oficial da União, Brasília, 31 de janeiro de 1985.

Decreto n. 97.688 de 25 de abril de 1989. Cria o Parque Nacional do Superagüi. Diário Oficial da União, Brasília, 25 de abril de 1989.

Lei n. 4.771, de 15 de setembro de 1965. Institui o novo Código Florestal Brasileiro. Diário Oficial da União, Brasília, 16 de setembro de 1965.

Lei n. 9.513, de 20 de novembro de 1997. Amplia os limites do Parque nacional do Superagüi, criado pelo Decreto no 97.688, de 25 de abril de 1989. Diário Oficial da União, Brasília, p. 27181, 21 de novembro de 1997.

Lei n. 9.985, de 18 de julho de 2000. Regulamenta o artigo 225, § $1^{\circ}$, incisos I, II, III e VII da Constituição Federal, institui o Sistema Nacional de Unidades de Conservação da Natureza e dá outras providências. Diário Oficial da União, Brasília, 19 de julho de 2000.

Ministério do Meio Ambiente. O Corredor Central da Mata Atlântica: uma nova escala de conservação as biodiversidade. Brasília, DF, 2006.

Ministério do Meio Ambiente. Portaria n. 132. Relator: Nilde Lago Pinheiro. 7 dezembro 2004. Diário Oficial da União, Brasília, n. 232, 08 dezembro 2004.

. Ministério do Meio Ambiente. Portaria n. 150. Relator: Claudio Langone. 8 maio 2006. Diário Oficial da União, Brasília, n. 93, p. 71-73, 17 maio 2006.

Ministério do Meio Ambiente. Resolução do Conselho Nacional do Meio Ambiente - CONAMA n. 13 de 6 de dezembro de 1990. Diário Oficial da União, Brasília, 6 dez 1990.

CAMPOS, J. B.; COSTA FILHO, L. V. da. Sistema ou conjunto de Unidades de Conservação? In: CAMPOS, J. B.; TOSSUlinO, M. de G. P.; MÜLLER, C. R. C. (Org.). Unidades de Conservação: ações para valorização da biodiversidade. Curitiba: Instituto Ambiental do Paraná, 2006.

CARPANEZZI, O. T. B.; WOEHL, J. H.; MUCHAILH, M. C. Sistema de manutenção, recuperação e proteção da reserva florestal legal e áreas de preservação permanente. In: CAMPOS, J. B.; TOSSULINO, M. de G. P.; MÜLlER, C. R. C. (Orgs.). Unidades de Conservação: ações para valorização da biodiversidade. Curitiba: Instituto Ambiental do Paraná, 2006. p. 193-201.

DAVEY, A. G.; PHILlIPS, A. National System Planning for Protected Areas. Gland: IUCN - the World Conservation Union, 1998.

DUDLEY, N.; PARISH, J. Closing the Gap - creating ecologically representative Protected Area Systems: a guide to conducting the gap assessments of protected area systems for the Convention on Biological Divesity. Montreal: Secretariat of the Convention on Biological Diversity, 2006. (Thechnical Series, n. 24).

FBPN - Fundação O Boticário de Proteção à Natureza. Áreas naturais Protegidas - Reserva Particular do Patrimônio Natural Salto Morato. Disponível em: <http://internet.boticario.com.br/ portal/site/fundacao/menuitem.0f476cf2dec0227de4e25afce2008a0c?epi_menuGrafico=Areas_Naturais\& epi_iten=Reserva+Natural+SaltoMorato\&item_Menu=2>. Acesso em: jan 2008.

FERNANDEZ, F. A. S. Efeitos da fragmentação de ecossistemas: a situação das Unidades de Conservação. In: CONGRESSO BRASILEIRO DE UNIDADES DE CONSERVAÇÃO, 1, 1997, 
Curitiba. Anais... Curitiba: Instituto Ambiental do Paraná, Universidade Livre do Meio Ambiente, Rede Nacional Pró-Unidades de Conservação, 1997. 2 v. p. 48-68.

O poema imperfeito: crônicas de biologia, conservação da natureza, e seus heróis. Curitiba: Universidade Federal do Paraná, 2000.

FONSECA, G. A. B. da; PINTO, L. P. de S.; RYLANDS, A. B. Biodiversidade e Unidades de Conservação. In: CONGRESSO BRASILEIRO DE UNIDADES DE CONSERVAÇÃO, 1, 1997, Curitiba. Anais... Curitiba: Instituto Ambiental do Paraná, Universidade Livre do Meio Ambiente, Rede Nacional Pró-Unidades de Conservação, 1997. 2 v. p. 262-285.

FORMAN, R. T. T. Land Mosaics: the ecology of landscapes and regions. New York: Cambridge University Press, 1995.

FORMAN, R. T. T.; GODROM, M. Landscape ecology. USA: J. Wiley, 1986.

INSTITUTO AMBIENTAL DO PARANÁ (IAP). Programa de desenvolvimento sustentável da Área de Proteção Ambiental de Guaraqueçaba. Curitiba: Universidade Livre do Meio Ambiente, Sociedade de Pesquisa em Vida Selvagem e Educação Ambiental, 1999.

INTITUTO BRASILEIRO DE MEIO AMBIENTE E DOS RECURSOS NATURAIS RENOVÁVEIS (IBAMA). Áreas Protegidas: Estação Ecológica de Guaraqueçaba. Disponível em: <http://www.ibama.gov.br/siucweb/mostraUc.php?seqUc=71>. Acesso em: jan 2008.

INSTITUTO PARANAENSE DE DESENVOLVIMENTO ECONÔMICO E SOCIAL (IPARDES). Zoneamento ecológico-econômico da Área de Proteção Ambiental de Guaraqueçaba. Curitiba, 1997. Zoneamento da Área de Proteção Ambiental de Guaraqueçaba. Curitiba, 2001.

MARENZI, R. C. Ecologia da paisagem como instrumento de apoio ao zoneamento de uso. In: CONGRESSO BRASILEIRO DE UNIDADES DE CONSERVAÇÃO, 2, 2000, Campo Grande. Anais... Campo Grande: Rede Nacional Pró-Unidades de Conservação, Fundação O Boticário de Proteção à Natureza, 2000. 2 v. p. 22-31.

METZGER, J. P. Estrutura da Paisagem: o uso adequado de métricas. In: CULLEN JUNIOR, L.; RUDRAN, R.; VALlADARES-PADUA, C. (Orgs.). Métodos de Estudos em Biologia da Conservação e Manejo da Vida Silvestre. Curitiba: Universidade Federal do Paraná, 2003. p. 423-453.

MIKICH, S. B.; BÉRNILS, R. S. Livro vermelho da fauna ameaçada no estado do Paraná. Curitiba: Instituto Ambiental do Paraná. 2004.

MILANO, M. S. Estudos da paisagem na avaliação de impactos ambientais. Curitiba, 1990.

Mitos no manejo de Unidades de Conservação no Brasil, ou a verdadeira ameaça. In: CONGRESSO BRASILEIRO DE UNIDADES DE CONSERVAÇÃO, 2., 2000, Campo Grande. Anais... Campo Grande: Rede Nacional Pró-Unidades de Conservação, Fundação O Boticário de Proteção à Natureza, 2000. 2 v. p. 11-25.

MILLER, K. R. Evolução do conceito de áreas de proteção - oportunidades para o século XXI. In: CONGRESSO BRASILEIRO DE UNIDADES DE CONSERVAÇÃO, 1, 1997, Curitiba. Anais... Curitiba: Instituto Ambiental do Paraná, Universidade Livre do Meio Ambiente, Rede Nacional PróUnidades de Conservação, 1997. 2 v. p. 3-21.

PÁDUA, M. T. J. Unidades de Conservação muito mais do que atos de criação e planos de manejo. In: MILANO, M. S. (Org.). Unidades de Conservação: atualidades e tendências. Curitiba: Fundação O Boticário de Proteção à Natureza, 2002. p. 3-13.

PARANÁ. Secretaria de Estado do Meio Ambiente e Recursos Hídricos / Instituto Ambiental do Paraná. Portaria n. 184. Relator: Lindsley da Silva Rasca Rodrigues. 2 setembro 2004. Diário Oficial do Estado do Paraná, Curitiba, n. 6811, 13 setembro 2004. 
PHILLIPS, A. Management Guidelines for IUCN Category V Protected Areas: Protected Landscapes/Seascapes. Gland: IUCN - the World Conservation Union, 2002.

PRIMACK, R. B.; RODRIGUES, E. Biologia da conservação. 3. ed. Londrina: Editora Vida, 2002.

RESERVA DA BIOSFERA DA MATA ATLÂNTICA (RBMA). A reserva da Biosfera da Mata Atlântica. Disponível em: 〈http://www.rbma.org.br/rbma/rbma_1_textosintese.asp>. Acesso em: dez. 2006 .

SOCIEDADE DE PESQUISA EM VIDA SELVAGEM E EDUCAÇÃO AMBIENTAL (SPVS). Plano integrado de conservação para a região Guaraqueçaba, Paraná, Brasil. Curitiba: Sociedade de Pesquisa em Vida Selvagem e Educação Ambiental, 1992.

Portaria do IAP cria nova RPPN em Antonina. Boletim Informativo: setembro de 2004. Disponível em: <http://www.spvs.org.br/download/boletins/biset04.htm>. Acesso em: jan. 2008.

THOMAS, L; MIDDLETON, J. Guidelines for Management Planning of Protected Areas. Gland: IUCN - the World Conservation Union, 2003.

TOSSUlino, M. de G. P.; MUCHAiLH, M. C.; CAMPOS, J. B. A importância do correto enquadramento das Unidades de conservação para a sua efetividade. In: CAMPOS, J. B.; TOSSULINO, M. de G. P.; MÜLlER, C. R. (Orgs..). Unidades de Conservação: ações para valorização da biodiversidade. Curitiba: Instituto Ambiental do Paraná, 2006. p. 259-277.

VIVEKANANDA, G. Parque Nacional do Superagüi: presença humana e os objetivos de conservação. Dissertação (Mestrado em Engenharia Florestal) - Setor de Ciências Agrárias, Universidade Federal do Paraná, Curitiba, 2001. 